Check for updates

Cite this: RSC Adv., 2018, 8, 25304

\title{
Polybenzimidazole/Nafion hybrid membrane with improved chemical stability for vanadium redox flow battery application $\uparrow$
}

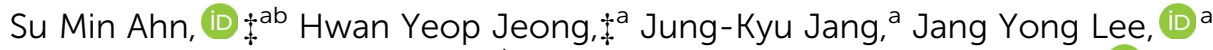 \\ Soonyong So, ${ }^{a}$ Young Jun Kim, ${ }^{b}$ Young Taik Hong*a and Tae-Ho Kim (DD *a
}

\begin{abstract}
In order to increase the chemical stability of polybenzimidazole (PBI) membrane against the highly oxidizing environment of a vanadium redox flow battery (VRFB), PBI/Nafion hybrid membrane was developed by spray coating a Nafion ionomer onto one surface of the PBI membrane. The acid-base interaction between the sulfonic acid of the Nafion and the benzimidazole of the PBI created a stable interfacial adhesion between the Nafion layer and the PBI layer. The hybrid membrane showed an area resistance of $0.269 \Omega \mathrm{cm}^{2}$ and a very low vanadium permeability of $1.95 \times 10^{-9} \mathrm{~cm}^{2} \mathrm{~min}^{-1}$. The Nafion layer protected the $\mathrm{PBI}$ from chemical degradation under accelerated oxidizing conditions of $1 \mathrm{M} \mathrm{VO}_{2}^{+} / 5 \mathrm{M}$ $\mathrm{H}_{2} \mathrm{SO}_{4}$, and this was subsequently examined in spectroscopic analysis. In the VRFB single cell performance test, the cell with the hybrid membrane showed better energy efficiency than the Nafion cell with $92.66 \%$ at $40 \mathrm{~mA} \mathrm{~cm}{ }^{-2}$ and $78.1 \%$ at $100 \mathrm{~mA} \mathrm{~cm}^{-2}$ with no delamination observed between the Nafion layer and the PBI layer after the test was completed.
\end{abstract}

Received 8th May 2018

Accepted 8th July 2018

DOI: 10.1039/c8ra03921f

rsc.li/rsc-advances

of active species, high chemical and mechanical stabilities in

\section{Introduction}

With the spread of renewable energy with large power load fluctuations, such as solar energy or wind energy, the need for large scale energy storage systems is increasing..$^{1-6}$ The vanadium redox flow battery (VRFB) is a promising energy storage system due to the advantage of using the same element with different states of oxidation to avoid cross contamination, along with its high energy density, high energy efficiency, and long cycle life. ${ }^{5}$ The VRFB is composed of anolyte, V(III)/V(II), and catholyte, $\mathrm{V}(\mathrm{v}) / \mathrm{V}(\mathrm{Iv})$, which are filled with different redox couples stored in separate external storage tanks. ${ }^{7}$ During the charge process, the electrolytes are pumped from electrolyte storage tanks to the electrodes, where $\mathrm{V}(\mathrm{Iv})$ is oxidized to $\mathrm{V}(\mathrm{v})$ in the cathode and V(III) is reduced to V(II) in the anode, converting electric energy to chemical energy. ${ }^{6}$ In order to separate the two electrolytes containing different oxidation states of vanadium ions and to conduct transferring ions $\left(\mathrm{H}^{+}, \mathrm{SO}_{4}{ }^{2-}\right)$, a membrane must exist between the anolyte and the catholyte. ${ }^{8}$ The requisites for the membrane are good ion conductivity, low crossover

\footnotetext{
${ }^{a}$ Membrane Research Center, Korea Research Institute of Chemical Technology (KRICT), 141 Gajeong-ro, Yuseong-gu, Daejeon 34114, Republic of Korea. E-mail: ythong@krict.re.kr; thkim@krict.re.kr

${ }^{b}$ School of Chemical Engineering, Sungkyunkwan University, Suwon, Kyunggi 440-746, Republic of Korea

$\dagger$ Electronic supplementary information (ESI) available. See DOI: $10.1039 / \mathrm{c} 8 \mathrm{ra03921f}$

$\ddagger$ These authors contributed equally to this work.
}

a highly oxidative environment, and low cost. ${ }^{5}$

Generally, cation exchange membrane (CEM) and anion exchange membrane (AEM) are used for VRFB membranes. Nafion is commonly used as CEM for its high ionic conductivity and adequate chemical stability due to its hydrophobic backbone and sulfonic acid terminated side chains, although it poses a problem of high crossover rate of vanadium ions, leading to a decrease in coulombic efficiency (CE) and capacity fading, and also its high cost., ${ }^{9,10}$ Apart from Nafion, hydrocarbon-based sulfonated membranes with low $\mathrm{VO}^{2+}$ permeability and good proton conductivity for its rigid aromatic backbone and high ion exchange capacity are considered as CEMs for VRFBs. ${ }^{11,12}$ Despite all their advantages, there are still issues of low resistances to vanadium species (high susceptibility to $\mathrm{VO}_{2}{ }^{+}$ion caused by the electron-rich aromatic group in the hydrocarbon-based membranes) and poor oxidation stability. ${ }^{13} \mathrm{AEM}$, which conducts anions such as $\mathrm{SO}_{4}{ }^{2-}$ has been developed for its low vanadium crossover rate compared to the conventional CEM, which can be explained by the Donnan exclusion effect, defined as an electrostatic repulsion between the positive functional groups in the AEM and the positive vanadium ions. ${ }^{14,15}$ Regardless of its low vanadium crossover rate, AEM also features a drawback of low chemical stability in highly oxidative environment. ${ }^{16}$ In order to enhance the disadvantages of these ion exchange membranes, membranes that utilize the size of pores to let only specific size of ions to cross by, also called the size exclusion effect, have been developed. ${ }^{17-19}$ Porous membranes without ion exchange group have 
shown improvements in stability, in spite of displaying a problem of vanadium crossover and complicated processing. ${ }^{20}$

There is an ongoing research for a different type of membrane that can be used in VRFB, using polybenzimidazole (PBI). ${ }^{21-23}$ Pristine PBI membrane is an electrically inert polymer displaying a very low conductivity of around $10^{-12} \mathrm{~S} \mathrm{~cm}^{-1} \cdot{ }^{24}$ However, it possesses a partially negative nitrogen in the benzimidazole group, which can create an acid-base complex when doped with acid. ${ }^{25,26}$ Proton transport in acid-doped PBI is mediated by the acid molecules that are dissolved in the polymer matrix. ${ }^{27}$ The fixed positive charge prevents the vanadium ion crossover due to the Donnan exclusion effect, resulting in low permeability to vanadium species and high $\mathrm{CE}^{28}$ PBI membrane also exhibits good thermal and chemical stability, high glass transition temperature, and high mechanical strength.$^{29}$ Nevertheless, most studies on PBI electrolyte membrane for VRFB are focused in porous membranes because they do not show sufficient ion conductivity under standard sulfuric acid concentration (3-4 M) of vanadium electrolyte due to the low acid doping capability. ${ }^{19,30}$ By adding pores to the membrane, PBI has been widely used as porous membrane, increasing the acid doping level and improving the conductivity of acid doped PBI membrane. ${ }^{18}$

Enhanced acid uptake property of dense PBI membrane based on poly[2,2'-(2-benzimidazole- $p$-phenylene)-5,5'-bibenzimidazole] (BI $p$ PBI), which has an additional benzimidazole side group, was studied previously in our team. ${ }^{31}$ The inclusion of additional benzimidazole side group increased the acid absorption capability and induced its amorphous structure with high free volume, contributing to better proton conductivity and lower resistance. Also, the nitrogen in the additional benzimidazole group augmented the Donnan exclusion effect, leading to lower permeability to vanadium ions. BI $p$ PBI showed cell performance with high CEs (>99\%) and energy efficiencies (EEs) (78-95\%) under a wide range of current densities (20-100 $\mathrm{mA} \mathrm{cm}{ }^{-2}$ ). In the in situ chemical stability test of our previous study, where continuous charge and discharge cycles were carried out at $50 \mathrm{~mA} \mathrm{~cm}{ }^{-2}$, BI $p$ PBI had constant CE above 99\% and a stable EE with a slight decreasing trend after 500 cycles, indicating excellent long-term stability in highly acidic and oxidizing environment. However, in the ex situ chemical stability test, in which the membranes were soaked into a solution of $0.1 \mathrm{M} \mathrm{VO}_{2}^{+} / 5 \mathrm{M} \mathrm{H}_{2} \mathrm{SO}_{4}, \mathrm{BI} p \mathrm{PBI}$ displayed less degradation compared to a conventional hydrocarbon membrane, although Nafion 115 had better chemical stability than both membranes, indicating that additional research for improving chemical stability of BI $p$ PBI is needed.

Along with the study of different kinds of membranes composed of distinct polymer material as previously mentioned, study of hybrid membranes with at least two different polymer materials combined is steadily progressing. ${ }^{32-35}$ However, most of these hybrid membranes are generally orientated to improve the ion selectivity by integrating an additional layer. ${ }^{36-38}$ For instance, Austing et al. dipped polyethylenimine and Nafion ionomer alternatively to Nafion layer using a layer-by-layer (LbL) technique, increasing the ion selectivity towards proton and reducing vanadium cross over. ${ }^{38}$ Similarly, to improve ion selectivity, Li et al. deposited ultrathin
Nafion film onto the poly(ether sulfone)-sulfonated poly(ether ether ketone) porous membranes. ${ }^{36}$ These hybrid membranes showed improvements in ion selectivity and reduction of vanadium crossover, but still have a limitation in increasing the chemical stability.

To increase the chemical stability of hydrocarbon membrane, our team collaborated in developing a hydrocarbon/ Nafion bilayer membrane with a mechanical nano-fastener, where Nafion was applied onto a hydrocarbon membrane via 3D-interface interlocking (3D-IIL) method, a ball and socket joint structure that binds these chemically different structures with no additional interfacial resistance. ${ }^{39}$ The chemically dissimilar structures of hydrocarbon and perfluorinated Nafion membranes cause delamination when combined, hence, a strong interfacing adhesion needs to be achieved at the interface. The 3D-IIL fastened hydrocarbon/Nafion bilayer membrane showed excellent VRFB performance. The chemical stability was also superior compared to its pristine hydrocarbon membrane in the ex situ chemical stability test, indicating the protective layer of Nafion layer applied on top of the hydrocarbon membrane reduced oxidative degradation.

In this work, we developed a layered hybrid type membrane where Nafion ionomer was spray coated onto the BIpPBI membrane. The nitrogen in the benzimidazole group develops an acid-base complex with the Nafion ionomer, creating a strong interfacial adhesion preventing delamination. For this reason, a layered hybrid type membrane with excellent interfacial adhesion has been developed without any help of additional manufacturing process, such as 3D-IIL. The combined effect of Nafion's excellent chemical stability and BI $p$ PBI's low permeability to vanadium ions magnified the advantages of both polymers. The layered hybrid type membrane of $\mathrm{BI} p \mathrm{PBI} /$ Nafion showed low resistance and low permeability to vanadium ions. It also showed high $\mathrm{EE}$ and $\mathrm{CE}$ under different current densities in VRFB cell performance test.

\section{Experimental}

\subsection{Materials}

1,2-Phenylenediamine (99.5\%), phosphorous pentoxide (99\%), vanadium(Iv) oxide sulfate hydrate (97\%), vanadium(v) oxide (99.6\%), and dimethylformamide (DMF) were obtained from Aldrich. 3,3'-Diaminobenzidine (DABI, 98\%) and trimellitic anhydride (4-carboxyphthalic anhydride, 98\%) were acquired by TCI. Polyphosphoric acid (PPA, 116\%) and 1-methyl-2pyrrolidone (NMP) were purchased from Junsei Chemical. Sulfuric acid (95-97\%) was provided by Merck. Sodium bicarbonate, methanol, dimethyl sulfoxide (DMSO) were provided by Samchun Chemical, Korea. Nafion 115 and Nafion ionomer (D1021) were supplied by Dupont. All of the reagents and solvents above were handled without purification.

\subsection{Polymer synthesis and characterization}

2-Benzimidazole terephthalic acid (BITA), the monomer of $\mathrm{BI} p \mathrm{PBI}$, was synthesized as previously reported. ${ }^{25}$ Using the monomer, BITA, and DABI dissolved in PPA, BI $p$ PBI was 
synthesized via condensation polymerization as previously described. ${ }^{31}$ Deuterated dimethyl sulfoxide (DMSO- $\mathrm{d}_{6}$ ) was used as a nuclear magnetic resonance (NMR) solvent to be analyzed for ${ }^{1} \mathrm{H}$-NMR (Bruker $500 \mathrm{MHz}$ spectrometer).

\subsection{Membrane preparation and characterization}

BI $p$ PBI membranes were prepared using a solvent casting method, where the thickness was adjusted by the weight of $\mathrm{BI} p$ PBI mixed into the solution. BI $p$ PBI with various weights were dissolved in NMP, and was filtered using a syringe filter ( 5 $\mu \mathrm{m}$, Teflon). The solution was casted onto a glass plate in a $13 \times$ $13 \mathrm{~cm}^{2}$ silicon mold, gradually heated from $25^{\circ} \mathrm{C}$ to $60{ }^{\circ} \mathrm{C}$ over 24 h. During casting, the film thickness was controlled by adjusting the concentration and the amount of solution. The $\mathrm{BI} p$ PBI was then peeled off the plate by immersing in a water bath after cooling to room temperature (RT), and was dried on a vacuum plate and stored in a desiccator.

In order to prepare hybrid type membrane, $10 \mathrm{wt} \%$ Nafion was dissolved in DMSO. The thickness and the uniformity of the membrane can be adjusted by the spray coating process and the hot-press process. Nafion solution was sprayed onto the BI $p$ PBI membrane using a spray coater (LSC-300, Lithotech., Korea) operated with a nozzle air pressure of $250 \mathrm{KPa}$ with a moving speed of $50 \mathrm{~mm} \mathrm{~s}^{-1}$. Polymer solution was injected at a rate of $0.5 \mathrm{~mL} \min ^{-1}$ using a syringe pump. The spraying nozzle was moved in the $x$-axis direction at a travelling distance of $5 \mathrm{~mm}$. The sprayed membrane was then dried at $190{ }^{\circ} \mathrm{C}$ on a vacuum plate for 10 minutes, and a sprayed layer of 1-1.5 $\mu \mathrm{m}$ was obtained by one cycle of spraying. The number of spraying cycle was adjusted to obtain the desired thickness. After spraying, Nafion was evenly pressed using a hot-press with a temperature of $130{ }^{\circ} \mathrm{C}$ and pressure of $10 \mathrm{kgf} \mathrm{cm}^{-2}$ to decrease the fluctuation of the surface. The low $T_{\mathrm{g}}$ of Nafion, $110{ }^{\circ} \mathrm{C}$, which causes compression bonding, enables a uniform coating layer.

The membranes were cut into $2 \mathrm{~cm} \times 2 \mathrm{~cm}$ and were dried at $80{ }^{\circ} \mathrm{C}$ under vacuum for 2 days, and their thickness ( $\left.T_{\text {undoped }}\right)$, length $\left(L_{\text {undoped }}\right)$, and weight $\left(W_{\text {unoped }}\right)$ at dried state were measured. The membranes were immersed in $4 \mathrm{M} \mathrm{H}_{2} \mathrm{SO}_{4}$ for 2 days at RT for acid doping. The wet acid-doped PBI membranes were wiped lightly with Kimwipes, and their thickness $\left(T_{\text {wet }}\right)$, length $\left(L_{\text {wet }}\right)$, and weight $\left(W_{\text {wet }}\right)$ were measured. To measure solely the weights of the acid uptake ( $\left.W_{\text {doped }}\right)$, the wet aciddoped membranes were dried at $80{ }^{\circ} \mathrm{C}$ under vacuum for 2 days to remove water. The acid doping level (ADL), acid uptake $\left(W_{\mathrm{A}}\right)$, and water uptake $\left(W_{\mathrm{W}}\right)$ were explored using the following equations,

$$
\begin{gathered}
\mathrm{ADL}=\left[\left(W_{\text {doped }}-W_{\text {undoped }}\right) / M_{\mathrm{H}_{2} \mathrm{SO}_{4}}\right] /\left(W_{\text {undoped }} / M_{\mathrm{BI} p \mathrm{PBI}}\right) \\
W_{\mathrm{A}}(\mathrm{wt} \%)=\left[\left(W_{\text {doped }}-W_{\text {undoped }}\right) / W_{\text {undoped }}\right] \times 100 \\
W_{\mathrm{w}}(\mathrm{wt} \%)=\left[\left(W_{\text {wet }}-W_{\text {doped }}\right) / W_{\text {undoped }}\right] \times 100
\end{gathered}
$$

with $M_{\mathrm{H}_{2} \mathrm{SO}_{4}}$ and $M_{\mathrm{BI} p \text { PBI }}$ being the molecular weights of sulfuric acid (98.08 $\left.\mathrm{g} \mathrm{mol}^{-1}\right)$ and the repeat unit of the BIpPBI (424.5 $\mathrm{g}$ $\mathrm{mol}^{-1}$ ), respectively.

\subsection{Membrane permeability to vanadium ions and area resistance}

The permeability of vanadium ions passing across the Nafion, pristine $\mathrm{BI} p \mathrm{PBI}$, and hybrid-type membranes were measured using the following method. A membrane with an effective area of $2.86 \mathrm{~cm}^{2}$ was placed between the two cells of the diffusion cell. The $\mathrm{VO}^{2+}$ ions passing through the membrane was measured for permeability. The left cell was filled with $80 \mathrm{~mL}$ of $1.2 \mathrm{M} \mathrm{VOSO}_{4}$ in $3 \mathrm{M} \mathrm{H}_{2} \mathrm{SO}_{4}$ solution and right cell filled with $80 \mathrm{~mL}$ of $1.2 \mathrm{M} \mathrm{MgSO}_{4}$ in $3 \mathrm{M} \mathrm{H}_{2} \mathrm{SO}_{4}$, with both cells continuously stirred to prevent concentration polarization. The hybrid membranes were assembled with the Nafion layer faced toward $\mathrm{VOSO}_{4}$. The solution of the right cell was taken at regular intervals of $24 \mathrm{~h}$ to measure the $\mathrm{VO}^{2+}$ ion concentration in a quartz cell, using an ultraviolet-visible (UV-Vis) spectrometer (Agilent Technologies, Cary 8454 UV-Vis). The permeability of $\mathrm{VO}^{2+}$ ions through the membranes can be calculated by the following equation,

$$
\begin{aligned}
& V_{\mathrm{R}} \frac{\mathrm{d} C_{\mathrm{R}}(t)}{\mathrm{d} t}=A \frac{P}{L}\left(C_{\mathrm{L}}-C_{\mathrm{R}}(t)\right) \\
& P=\frac{L}{A} V_{\mathrm{R}} \frac{\mathrm{d} C_{\mathrm{R}}(t)}{\mathrm{d} t} \frac{1}{\left(C_{\mathrm{L}}-C_{\mathrm{R}}(t)\right)}
\end{aligned}
$$

with $V_{\mathrm{R}}$, the solution volume in the right cell, $C_{\mathrm{L}}$, the $\mathrm{VO}^{2+}$ concentration in the left cell, and $C_{\mathrm{R}}(t)$, the $\mathrm{VO}^{2+}$ concentration in the right cell as a function of time $(t)$. $A$ is the effective area of the membrane, $2.86 \mathrm{~cm}^{2}$, and $L$ is the thickness of the membrane. $P$ is the membrane permeability to $\mathrm{VO}^{2+}$ cations.

Area resistance (AR) can be assessed using an impedance analyzer connected with a two-probe clip-cell. The Nafion 115 and BI $p$ PBI membranes were immersed in $4 \mathrm{M} \mathrm{H}_{2} \mathrm{SO}_{4}$ at RT for 2 days beforehand. Using the following equation,

$$
R=\left(R_{1}-R_{2}\right) \times S
$$

with $R_{1}$ and $R_{2}$ being the electrical resistance of the membrane with the cell and without the cell, respectively, and $S$ corresponding to the effective area, $0.196 \mathrm{~cm}^{2}$, of the two-probe clipcell, the AR could be evaluated.

The ion conductivity can be obtained from the area resistance value above, using the following equation,

$$
\sigma=L / R A
$$

with $L$ corresponding to the thickness, $R$ being the resistance, and $A$ indicating the effective area of membrane.

\subsection{Ex situ chemical stability}

Before carrying out the ex situ chemical stability test, Nafion 115 , pristine $\mathrm{BI} p \mathrm{PBI}$, and hybrid-type membranes were first dried under vacuum at $80{ }^{\circ} \mathrm{C}$ for $24 \mathrm{~h}$. A special bottle that contains $20 \mathrm{~mL}$ of a $1 \mathrm{M} \mathrm{VO}_{2}{ }^{+} / 5 \mathrm{M} \mathrm{H}_{2} \mathrm{SO}_{4}$ solution with a hole in the bottom was made to measure ex situ chemical stability for only one side of the membrane, where the membrane was placed on the bottom with an effective area of $2.86 \mathrm{~cm}^{2}$ at $40{ }^{\circ} \mathrm{C}$ for $300 \mathrm{~h}$. The details for the experimental setup are described 
in ESI (Fig. S2 of ESI $\dagger$ ). Visible observations were made for any chemical degradation and were recorded in optical images. After the ex situ chemical stability test, the membrane was washed in $4 \mathrm{M} \mathrm{H}_{2} \mathrm{SO}_{4}$ to remove vanadium ions, and subsequently in deionized water to remove acid. Post analysis was assessed with the washed membrane, using ${ }^{1} \mathrm{H}$-NMR and scanning electron microscopy (SEM) (Tescan Mira 3 LMU FE6).

\subsection{VRFB single cell performance}

The VRFB single cell performance was evaluated by assembling VRFB cell by sandwiching a membrane with an effective area of $7 \mathrm{~cm} \times 7 \mathrm{~cm}\left(49 \mathrm{~cm}^{2}\right)$ between two carbon-felt electrodes, two flow frames, graphite bipolar plates (Standard Energy Inc.) which are used as current collectors, and copper plates. Both the Nafion 115 and $\mathrm{BI} p \mathrm{PBI}$ membranes did not go through the pre-treatment process. $80 \mathrm{~mL}$ of $1.65 \mathrm{M} \mathrm{V}^{3.5+}$ in $3 \mathrm{M} \mathrm{H}_{2} \mathrm{SO}_{4}$ solution was used for both positive and negative electrolytes, with the feed rate of electrolyte flowed at $80 \mathrm{~mL} \mathrm{~min}^{-1}$. The VRFB single cell performance was operated by a battery cycler system (WonATech, WBCS300M2), varying the current densities by $40,60,80$, and $100 \mathrm{~mA} \mathrm{~cm} \mathrm{~cm}^{-2}$ and cut-off voltages of charging and discharging were $1.6 \mathrm{~V}$ and $1.0 \mathrm{~V}$. Coulombic efficiency (CE), energy efficiency (EE), and voltage efficiency (VE) were obtained from charge-discharge process, and were calculated as the following,

$$
\begin{gathered}
\mathrm{CE}=\frac{\int I_{\mathrm{d}} \mathrm{d} t}{\int I_{\mathrm{c}} \mathrm{d} t} \times 100 \% \\
\mathrm{EE}=\frac{\int V_{\mathrm{d}} I_{\mathrm{d}} \mathrm{d} t}{\int V_{\mathrm{c}} I_{\mathrm{c}} \mathrm{d} t} \times 100 \% \\
\mathrm{VE}=\frac{\mathrm{EE}}{\mathrm{CE}} \times 100 \%
\end{gathered}
$$

where $V, I$, and $t$ are the voltage, current, and time, correspondingly. The subscripts $\mathrm{d}$ and $\mathrm{c}$ respectively indicate the discharge and charge processes. Post analysis after the VRFB single cell test took place using SEM.

\section{Results and discussion}

\subsection{Membrane preparation with Nafion spray coating}

$\mathrm{BI} p \mathrm{PBI}$ was polymerized from DABI and BITA via condensation polymerization using PPA as solvent, as previously reported. ${ }^{31}$ BI $p$ PBI has an inherent viscosity of $1.56 \mathrm{dL} \mathrm{g}^{-1}$ in $\mathrm{H}_{2} \mathrm{SO}_{4}$ solution at RT and concentration of $0.5 \%$, supporting its high molecular weight. BI $p$ PBI has good solubility to organic solvents because of its amorphous structure induced by the additional benzimidazole side group, eliminating the need to use hazardous solvent, such as methanesulfonic acid. Using NMP as solvent in solution casting method, BI $p$ PBI membranes were prepared with different thickness by adjusting the amount of weight of BIpPBI powder put into the solution.

Hybrid type membranes were fabricated by spray coating Nafion ionomer on one surface of BI $p$ PBI membranes varying the spraying thickness, shown in the schematic drawing in Fig. 1(a). From here on, the names of the hybrid membranes will be designated as $\mathrm{B} x \mathrm{~N} y$, with $x$ as the thickness of $\mathrm{BI} p \mathrm{PBI}$ layer in $\mu \mathrm{m}$ and $y$ as the thickness of Nafion layer in $\mu \mathrm{m}$. The hybrid type membranes with coated Nafion ionomer can be verified in the SEM images of Fig. 1 and S1 (ESI $\dagger$ ). To confirm the coating layer, hybrid membrane was analysed for $\mathrm{F}$ atoms in XPS analysis because Nafion contains F element in the molecular structure, while BI $p$ PBI is absent of F element. Fig. S1(c) $(\mathrm{ESI} \dagger)$ showed that the peaks of the $\mathrm{F}$ element appeared largely near the $686 \mathrm{eV}$ on the Nafion coated surface. However, no peak was found on the uncoated side.

In an actual application of VRFB, membrane degradation occurs at the positive electrolyte side where the $\mathrm{VO}_{2}{ }^{+}$ions induce chemical degradation. ${ }^{\mathbf{4 0}}$ Therefore, the chemically stable Nafion layer would face the catholyte when assembled in a VRFB cell. Both B20N5 be and B20N10 membranes have Nafion ionomer at one side of the hybrid membrane, and the other side displaying only pristine BI $p$ PBI membrane, as seen in Fig. S1 $(\mathrm{ESI} \dagger)$. The cross-sectional image also confirms that the upper layers of B20N5 (Fig. 1(b)) and B20N10 (Fig. 1(c)) membranes with uniformly thick Nafion ionomer are coated onto the BI $p$ PBI membrane. As we have expected, for hybrid-type membranes, stable interfacial adhesion without any noticeable defect was obtained successfully, as a result of strong acid-base complex between the benzimidazole group in BI $p$ PBI and sulfonic acid group in coated Nafion ionomers.

\subsection{Acid/water uptake and area resistance}

The general properties of acid doping level, acid uptake, and water uptake obtained from eqn (1)-(3) that were given in the experimental section, are shown in Table 1. Proton conducting ability of innate BI $p$ PBI can be acquired by doping with acid, which can be measured via acid doping level using eqn (1). Since Nafion does not develop an acid-base complex with the acid as the $\mathrm{BI} p$ PBI does with the nitrogen in the benzimidazole group, only the $\mathrm{BI} p \mathrm{PBI}$ proportions of the hybrid membranes of B20N5 and B20N10 were considered for ADL. All the

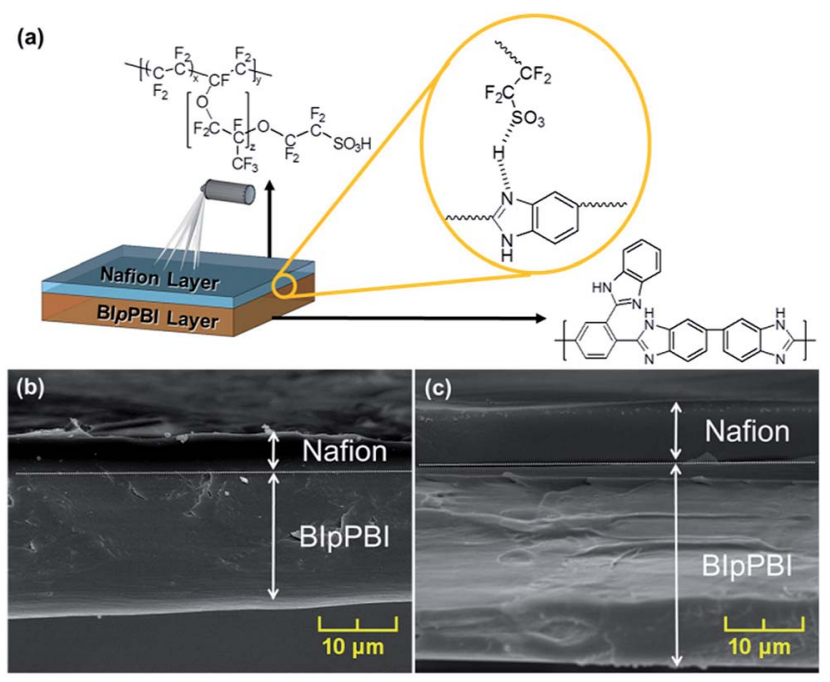

Fig. 1 (a) Schematic of the BIpPBI/Nafion hybrid membrane and its interface; cross sectional SEM image of (b) B20N5 and (c) B20N10. 
Table 1 The acid doping level and the acid/water uptake of the membranes $^{b}$

\begin{tabular}{llll}
\hline & $\mathrm{ADL}^{a}$ & $W_{\mathrm{A}}(\mathrm{wt} \%)$ & $W_{\mathrm{W}}(\mathrm{wt} \%)$ \\
\hline BI $p$ PBI $^{31}$ & 2.8 & 65.5 & 46.2 \\
B20N5 & 2.7 & 44.8 & 20.9 \\
B20N10 & 2.9 & 38.7 & 23.6 \\
Nafion 115 & - & 1.0 & 7.0
\end{tabular}

${ }^{a}$ The ADL is calculated only for the BIpPBI content. ${ }^{b}$ The measurements were done in $4 \mathrm{M}$ sulfuric acid.

membranes, BI $p$ PBI, B20N5, and B20N10, had similar ADLs of 2.7 to 2.9. BI $p$ PBI has three benzimidazole groups in the PBI repeat unit, which determines the bound acid content. ${ }^{31}$ Since ADL reaches approximately to three for the BI $p$ PBI and hybrid membranes, most of the nitrogen in the benzimidazole groups are protonated by the sulfuric acid, forming an acid-base complex. From here, we can conclude that the thickness of $\mathrm{BI} p$ PBI membrane or the existence of additional coated layer does not affect the acid absorbing capability of BI $p$ PBI membranes.

As stated in eqn (2) and (3), the $W_{\mathrm{W}}$ and the $W_{\mathrm{A}}$ are calculated considering the whole membrane weight, including both the $\mathrm{BI} p \mathrm{PBI}$ and the Nafion content. The pristine BIpPBI membrane showed $W_{\mathrm{A}}$ of $65.5 \mathrm{wt} \%$, demonstrating its excellent acid absorption ability. During the acid absorption process, water molecules were also absorbed into the BI $p$ PBI membrane due to the osmosis and hydrogen bonding with sulfuric acid absorbed, resulting in high $W_{\mathrm{W}}$ value of $46.2 \%$. However, in $4 \mathrm{M} \mathrm{H}_{2} \mathrm{SO}_{4}$ bath, the Nafion membrane showed $W_{\mathrm{A}}$ of $1.0 \mathrm{wt} \%$ and $W_{\mathrm{W}}$ of $7.0 \mathrm{wt} \%$, which are very low values because Nafion membrane does not create any acid-base interaction with sulfuric acid as BI $p$ PBI does. Hybrid membranes, which combine both BI $p$ PBI and Nafion, have intermediate values of $44.8 \mathrm{wt} \% W_{\mathrm{A}}$ and $20.9 \mathrm{wt} \% W_{\mathrm{W}}$ for B20N5 membrane and $38.7 \mathrm{wt} \% W_{\mathrm{A}}$ and $23.6 \mathrm{wt} \% W_{\mathrm{W}}$ for B20N10 membrane.

The ARs of pristine BI $p$ PBI and hybrid membranes, B20N5 and B20N10, were measured at $4 \mathrm{M} \mathrm{H}_{2} \mathrm{SO}_{4}$, shown in Fig. 2 . Nafion 115 had high AR of $0.25 \Omega \mathrm{cm}^{2}$ with a thickness of 125 $\mu \mathrm{m}$, which was 4-5 times thicker than other membranes being evaluated. BI $p$ PBI with a thickness of $25 \mu \mathrm{m}$ displayed AR of $0.117 \Omega \mathrm{cm}^{2}$ and ion conductivity value of $0.0141 \mathrm{~S} \mathrm{~cm}^{-1}$ using

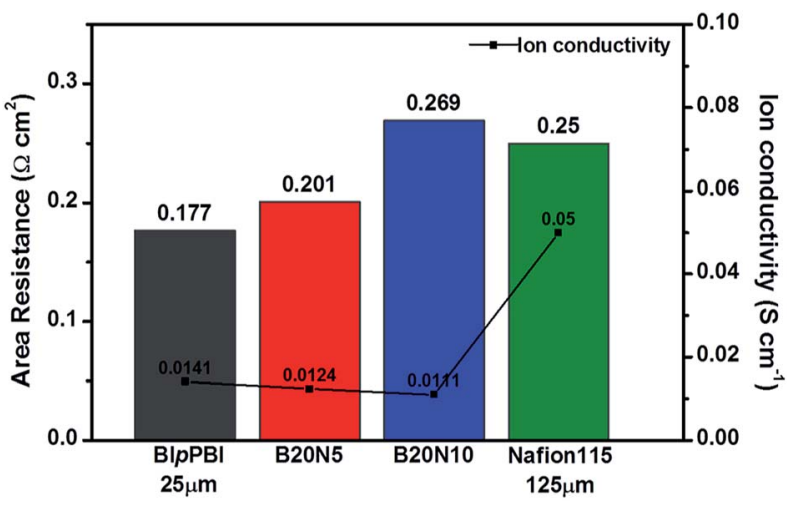

Fig. 2 The AR of the membranes and ion conductivities. eqn (6). Nafion 115 showed larger AR of $0.25 \Omega \mathrm{cm},{ }^{2}$ but relatively higher ion conductivity of $0.05 \mathrm{~S} \mathrm{~cm}^{-1}$. This is due to the Nafion 115's thickness of $125 \mu \mathrm{m}$, in which the thickness itself can generate large AR. However, when calculating the ion conductivity shown in eqn (6), the equation is divided by the thickness value, and thus the tendency for ion conductivity is reversed. For the hybrid B20N5 and B20N10 membranes, the ARs were $0.201 \Omega \mathrm{cm}^{2}$ and $0.269 \Omega \mathrm{cm}^{2}$, respectively, and the values of ion conductivity were $0.124 \mathrm{~S} \mathrm{~cm}^{-1}$ and $0.111 \mathrm{~S} \mathrm{~cm}^{-1}$, respectively. Using the AR per $1 \mu \mathrm{m}$ for BI $p$ PBI and Nafion membranes, theoretical resistance can be calculated, which were obtained as $0.151 \Omega \mathrm{cm}^{2}$ and $0.161 \Omega \mathrm{cm}^{2}$, respectively. This values are lower than the measured area resistance, indicating that an interfacial resistance has occurred between BI $p$ PBI layer and Nafion layer. For this reason, the two hybrid membranes have higher ARs than BIpPBI and Nafion membranes and slightly lower ion conductivity values.

\subsection{Vanadium permeability}

Membrane permeability was evaluated by measuring the $\mathrm{VO}^{2+}$ ions passing through the membrane in a diffusion cell using UV-Vis spectrometer. The $\mathrm{VO}^{2+}$ concentration along with exposed time is represented in Fig. 3, together with the table of vanadium permeability after normalizing with standardized equation. ${ }^{31}$ Membranes with low vanadium permeability are crucial in VRFB application for high CEs. The pristine BI $p$ PBI membrane and two hybrid membranes (B20N5 and B20N10) have very low permeability of $3.45 \times 10^{-8} \mathrm{~cm}^{2} \min ^{-1} 2.65 \times$ $10^{-9} \mathrm{~cm}^{2} \mathrm{~min}^{-1}$ and $1.95 \times 10^{-9} \mathrm{~cm}^{2} \mathrm{~min}^{-1}$, respectively, compared to Nafion 115 membrane with the vanadium permeability of $3.48 \times 10^{-7} \mathrm{~cm}^{2} \mathrm{~min}^{-1}$. The vanadium ions are less permeable to $\mathrm{BI} p$ PBI membrane because of $\mathrm{BI} p$ PBI's intrinsic nature of forming acid-base complex, which produces fixed positive charges, repelling vanadium cations (Donnan exclusion). In addition, for the hybrid membrane with coated Nafion ionomer, the acid-base complexes between sulfonic acid and benzimidazole groups that are created at the interface between the two layers can further prevent permeation of vanadium ions. ${ }^{38}$ As a result, hybrid membranes, B20N5 and B20N10, have lower vanadium permeability than pristine BI $p$ PBI and Nafion 115. Among them, B20N10 has the lowest

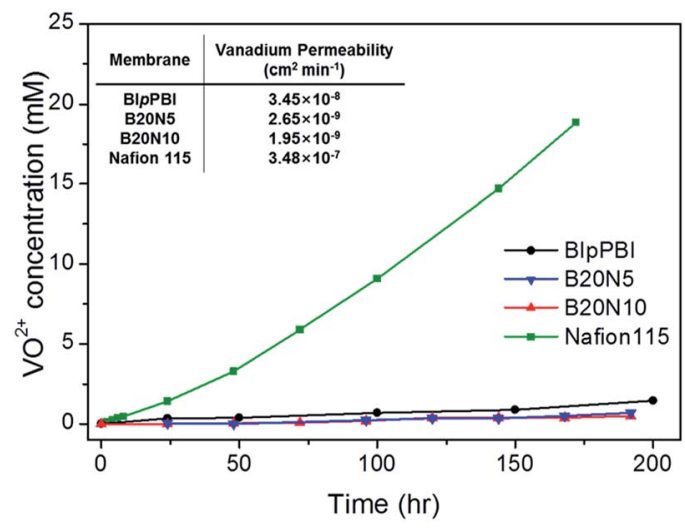

Fig. 3 The vanadium permeability of the membranes. 
vanadium permeability because of the thick Nafion layer. The $\mathrm{AR}$ and the vanadium permeability directly affect the VRFB cell performance in terms of VE and CE, which will be discussed in detail in VRFB single cell performance section.

\subsection{Ex situ stability}

Nafion was coated onto the BIpPBI membrane in this study, since Nafion is renowned for its excellent chemical stability against the highly oxidizing $\mathrm{VO}_{2}{ }^{+}$ions. Ex situ chemical stability was tested in a $1 \mathrm{M} \mathrm{VO}_{2}^{+} / 5 \mathrm{M} \mathrm{H}_{2} \mathrm{SO}_{4}$ solution at $40{ }^{\circ} \mathrm{C}$ for $300 \mathrm{~h}$, which corresponds to a highly accelerated oxidizing condition. Specifically for the testing of the hybrid membranes, a novel type of testing apparatus was devised to measure only one side of the membrane, as shown in Fig. 4(a and b) and S4(a-c) (ESI $\dagger$ ). A cylindrical test tube with a hollow opening at the bottom (Fig. S2(a) of ESI†) was encased in a metal container (Fig. S2(b) of ESI $\dagger$ ). The final assembly was constructed with the membrane sandwiched between two rubber gaskets laid between the hole of the cylindrical test tube and the chemically stable PTFE plate (Fig. S2(c) of ESI $\dagger$ ). With this customized testing apparatus, only one side of the membrane is exposed to $1 \mathrm{M} \mathrm{VO}_{2}^{+} / 5 \mathrm{M} \mathrm{H}_{2} \mathrm{SO}_{4}$ oxidizing solution, while the other side of the membrane remained intact. For the hybrid membranes of B20N5 and B20N10, the Nafion sides are exposed to $1 \mathrm{M} \mathrm{VO}_{2}{ }^{+} /$ $5 \mathrm{M} \mathrm{H}_{2} \mathrm{SO}_{4}$ to assess whether Nafion coating protects the BI $p$ PBI membrane from the highly oxidizing environment when applied in VRFB cell.
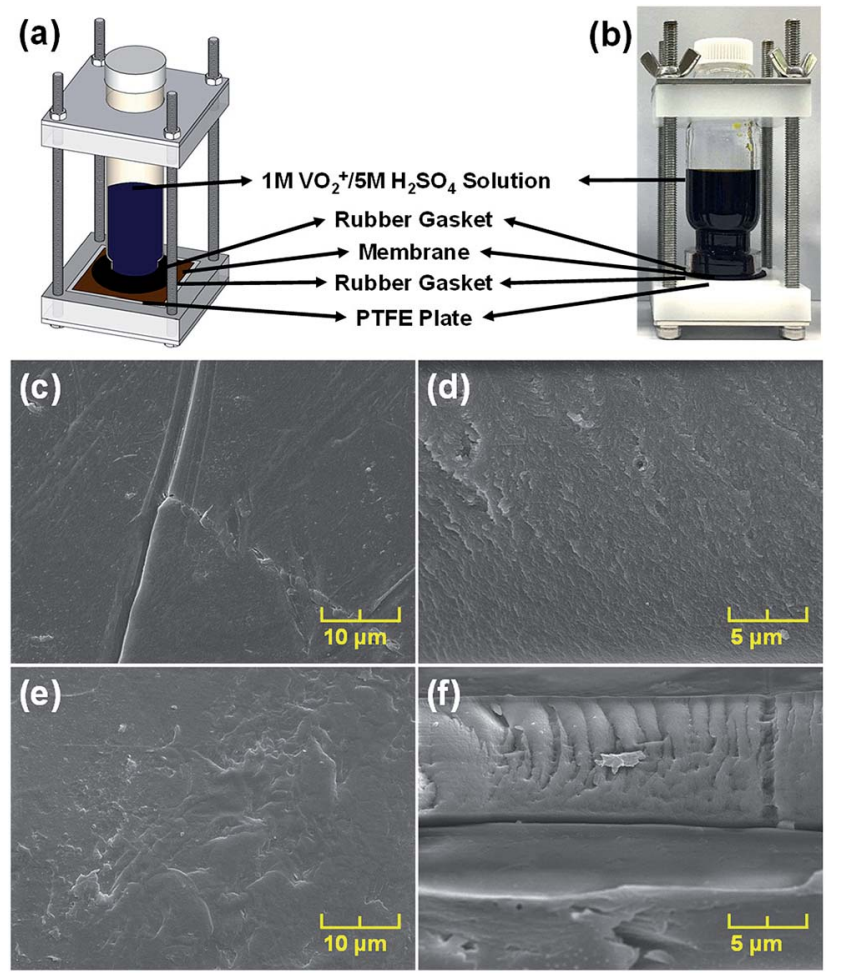

Fig. 4 (a) Schematic and (b) actual photo of the ex situ chemical stability testing apparatus; SEM images of (c) BIpPBI surface (d) cross section and (e) B20N5 surface (f) cross section.
The chemical degradation of the BI $p$ PBI and the hybrid membranes resulted from the strongly oxidizing $\mathrm{VO}_{2}{ }^{+}$ions, which can be visibly seen in Fig. S2(d and e) (ESI $\dagger$ ). When the $\mathrm{BI} p$ PBI membrane, weakened by the $\mathrm{VO}_{2}{ }^{+}$ions, was teared off from the rubber gasket after the test, it created a perforation in the middle (Fig. S2(d) in ESI $\dagger$ ). On the contrary, hybrid type membranes, B20N10 and B20N5, did not disintegrate during the tear off, and remained comparatively intact with only minor cracks (Fig. S2(e) in ESI $\dagger$ ). SEM analysis was done after the ex situ chemical stability test on the surface and the cross section of the membranes, as seen in Fig. 4(c-f). After the accelerated test in $1 \mathrm{M} \mathrm{VO}_{2}{ }^{+} / 5 \mathrm{M} \mathrm{H}_{2} \mathrm{SO}_{4}$ solution, fractures were seen on the surface representing chemical degradation, especially for BI $p$ PBI membrane (Fig. 4(c)). In the cross sectional image, more ruptures were found on the BI $p$ PBI membrane (Fig. 4(d)) compared to the hybrid membrane (Fig. 4(f)). For hybrid membranes of B20N5 (Fig. 4(e and f)) and B20N10 (Fig. S2(f and g) in ESI†), Nafion layer was still attached to the BIpPBI layer when the membranes were pulled off from the rubber gasket. Even though the hybrid membranes were wrinkled, fractures were barely observable. The accelerated oxidizing environment affected the hybrid membranes. However, the Nafion protecting layer deterred the chemical degradation, and thus the membranes were kept all in one piece.

${ }^{1} \mathrm{H}-\mathrm{NMR}$ analysis was carried out to the membranes after the ex situ chemical stability test, and was compared to intact BI $p$ PBI membrane, which had no chemical stability test done, presented in Fig. 5. BI $p$ PBI membrane when exposed to $1 \mathrm{M}$ $\mathrm{VO}_{2}{ }^{+} / 5 \mathrm{M} \mathrm{H}_{2} \mathrm{SO}_{4}$ solution showed pronounced change in shape at 7.6-8.2 ppm (d, f, g, h peaks), suggesting considerable chemical degradation has occurred on the phenylene structure in the benzimidazole rings in the highly oxidizing environment of $1 \mathrm{M} \mathrm{VO}_{2}{ }^{+} / 5 \mathrm{M} \mathrm{H}_{2} \mathrm{SO}_{4}$ solution. Also a new peak appeared around $9.0 \mathrm{ppm}$, additionally confirming chemical degradation of the BI $p$ PBI membrane after the ex situ chemical stability test.
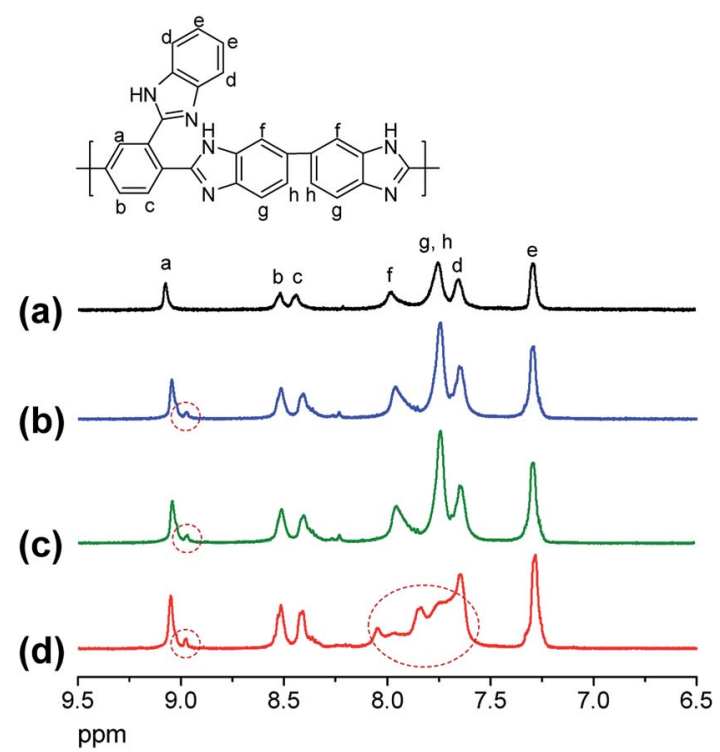

Fig. $5{ }^{1} \mathrm{H}-\mathrm{NMR}$ spectra of (a) pristine BlpPBI; (b) B20N5, (c) B20N10, and (d) BIpPBI after ex situ chemical stability test. 
For the hybrid membranes, B20N5 and B20N10, the change of the peak shape was not observed at 7.6-8.2 ppm after the ex situ chemical stability test. Also, the intensities of the newly formed peaks of hybrid membranes at $9.00 \mathrm{ppm}$ were smaller than the peak of chemically degraded BI $p$ PBI membrane, signifying that hybrid membranes are less affected by the $\mathrm{VO}_{2}{ }^{+}$ ions in the accelerated ex situ chemical stability test, as expected.

\subsection{VRFB single cell performance}

VRFB single cell performances were analysed for single cells with four different kinds of membranes, BI $p$ PBI, B20N10 and Nafion 115, under various current densities (40, 60, 80, $100 \mathrm{~mA}$ $\mathrm{cm}^{-2}$ ), evaluating for EE, CE, and VE, shown in Fig. 6. When assembling the membrane in the single cell, the Nafion coated layer was faced toward the catholyte due to $\mathrm{VO}_{2}{ }^{+}$ions presented in the positive electrolyte being the primary reason for membrane degradation. $\mathrm{CE}$, which is defined as the cell's discharge capacity over its charge capacity, is affected adversely by the diffusion of vanadium ions across the membrane. The single cell of Nafion 115 showed slight increase of CE from $96.6 \%$ to $97.1 \%$ with increasing current density from $40 \mathrm{~mA}$ $\mathrm{cm}^{-2}$ to $100 \mathrm{~mA} \mathrm{~cm}{ }^{-2}$ due to shorter crossover time of vanadium species. Single cells with BI $p$ PBI and B20N10 showed very high CEs ( $>99 \%)$ throughout all current densities due to Donnan exclusion effect and acid-base complex interface preventing vanadium ions from crossing over the membrane, resulting in low vanadium permeability.

The VE is affected by the ohmic polarization and varies inversely with the current density. ${ }^{41}$ Larger area resistance of membrane enlarges the internal resistance in the VRFB operation, leading to an unfavorable influence over the VE. Although Nafion 115 membrane had the highest AR of $0.25 \Omega \mathrm{cm}^{2}$ due to its thickness of $125 \mu \mathrm{m}$, when applied to VRFB single cell, all three singles cells showed similar VEs of 90-91\%, 85-86\%, and $81 \%$ in 40,60 , and $80 \mathrm{~mA} \mathrm{~cm}{ }^{-2}$, correspondingly. At $40 \mathrm{~mA}$ $\mathrm{cm}^{-2}$, the single cell assembled with B20N10 had the highest VE of $91.39 \%$. However, as the current density increased to $100 \mathrm{~mA}$ $\mathrm{cm}^{-2}$, the B20N10 cell displayed the lowest VE of $76.08 \%$. At higher current density, the membrane resistance is more affected to the voltage efficiency. ${ }^{42}$ Therefore, B20N10 with the highest area resistance among the membranes, showed a larger drop of VE.

$\mathrm{EE}$, a product of $\mathrm{CE}$ and $\mathrm{VE}$, is the key parameter for the energy loss occurring during the charge-discharge process. With the combined effect of CE and VE, VRFB single cell fabricated with the hybrid membrane B20N10 showed highest EEs among the single cells with values of $92.66 \%, 87.55 \%$, and $82.2 \%$ in 40,60 , and $80 \mathrm{~mA} \mathrm{~cm}^{-2}$, in the respective order. However, at a high current density of $100 \mathrm{~mA} \mathrm{~cm}^{-2}$, the order of EE value reversed for BI $p$ PBI single cell (78.1\%) and B20N10 single cell (76.84\%) due to the high AR of B20N10. In spite of this overturn, the single cell assembled with B20N10 showed superior EE than the cell with Nafion 115 in all measured current densities. Cycling test was conducted to investigate long term stability of the membranes. Under $60 \mathrm{~mA} \mathrm{~cm}^{-2}$, the (a)

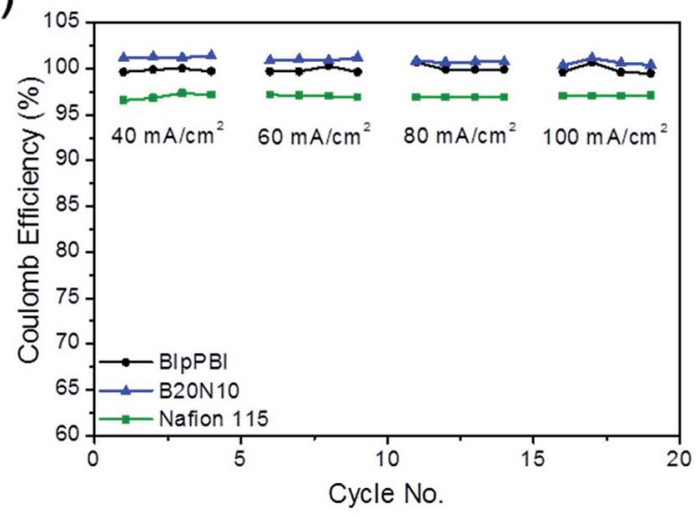

(b)

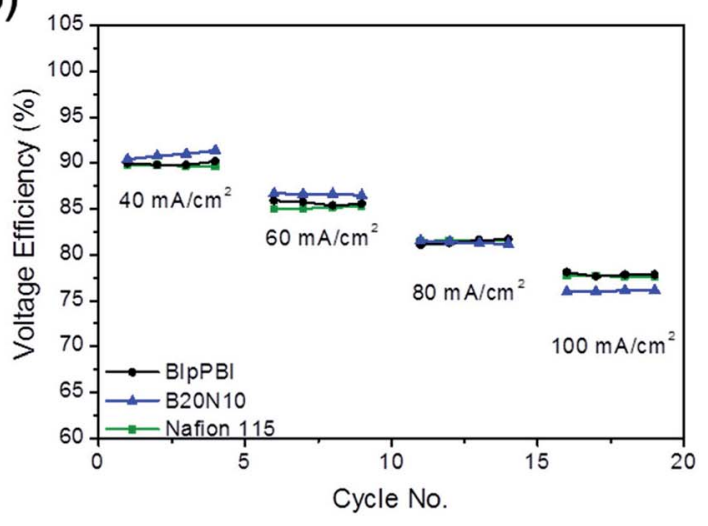

(c)

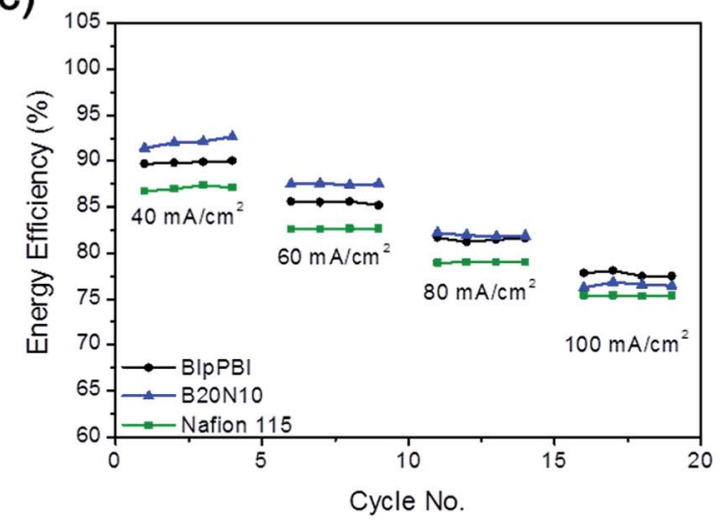

Fig. 6 (a) $C E$, (b) VE, (c) EE of VRFB single cell performance test.

continuous charge and discharge test was conducted without replacement of electrolyte for 300 cycles. Fig. S4 in ESI $\uparrow$ shows the cycling test efficiency and the discharge capacity of $\mathrm{BI} p \mathrm{PBI}$ and B20N10. For CE, both membranes maintained 100\% constantly due to low vanadium permeability. The BI $p$ PBI kept stable EE of $90-87 \%$ for 300 cycles, and B20N10 maintained EE of $87-85 \%$. Looking at the discharge capacity, BI $p$ PBI showed decrease of $28.3 \%$ and Nafion coated B20N10 showed decrease of $19.8 \%$ in discharge capacity after 300 cycles. This confirms the less capacity loss of B20N10, implying due to the lower vanadium permeability, relatively less capacity retention occured. The CE and EE of Nafion 115 were stable. However, 
due to rapid capacity fade, the capacity retention decreased to less than $50 \%$ at 100 cycle. $^{31}$ After the VRFB single cell performance test, the testing equipment was disintegrated to evaluate for any visible change in the membrane. No discernible delamination was observed after the test, implying that acid-base complex formed between the benzimidazole group of BI $p$ PBI and the sulfonic acid group of Nafion functions as a successful latch between the two layers. Post analysis was carried out for SEM images with B20N10 and BI $p$ PBI membranes to examine visually for any degradation in the surface or the cross section of the membrane after the VRFB single cell performance test, featured in Fig. S3 (ESI $\dagger$ ). The membrane degradation is less distinctive than the ex situ chemical stability test that used $1 \mathrm{M} \mathrm{VO}_{2}{ }^{+} / 5 \mathrm{M} \mathrm{H}_{2} \mathrm{SO}_{4}$, revealing that in an actual condition of VRFB, membranes do not go through deterioration as much as they did in the accelerated ex situ chemical stability test. Moreover, the BI $p$ PBI membrane (Fig. S3(d and e) in ESI $\dagger$ ) showed more roughness and jaggedness on the surface and more cavities on the cross sectional images than the B20N5 membrane (Fig. S3(a-c) in ESI $\dagger$ ), signifying that the Nafion protective coat on the surface of B20N5 deter membrane degradation against the oxidative environment of VRFB.

\section{Conclusions}

Nafion ionomer was successfully spray coated onto the BI $p$ PBI membrane and was evaluated for VRFB application. The acidbase complex formed between the nitrogen of benzimidazole group in the BI $p$ PBI layer and the sulfonic acid group of the Nafion layer holds these layers together with high interfacial adhesion. The hybrid membranes, B20N5 and B20N10, showed $W_{\mathrm{A}}$ of $44.8 \mathrm{wt} \%$ and $38.7 \mathrm{wt} \%$ and $W_{\mathrm{W}}$ of $20.9 \mathrm{wt} \%$ and $23.6 \mathrm{wt} \%$, respectively, but had similar ADLs (2.7 and 2.9) to the ADL of pristine BI $p$ PBI membrane (2.8). The hybrid membranes showed AR of $0.201 \Omega \mathrm{cm}^{2}$ for B20N5 membrane and $0.269 \Omega$ $\mathrm{cm}^{2}$ for B20N10 membrane. The hybrid membranes, B20N10 and B20N5, showed very low vanadium permeabilities of $1.95 \times$ $10^{-9} \mathrm{~cm}^{2} \mathrm{~min}^{-1}$ and $2.65 \times 10^{-9} \mathrm{~cm}^{2} \mathrm{~min}^{-1}$, respectively, accounted for Donnan exclusion effect and acid-base complex interface preventing the permeation of vanadium species. The excellent chemical stability of Nafion protective layer successfully hinders chemical degradation from highly oxidizing $\mathrm{VO}_{2}{ }^{+}$ species in the ex situ chemical stability test, supported by the results of SEM and ${ }^{1} \mathrm{H}-\mathrm{NMR}$. In the VRFB single cell performance, the single cell with B20N10 membrane showed higher EE than the single cell with Nafion membrane for all current densities measured. Moreover, when the membrane was disintegrated from the cell after the test, no delamination was observed proving that stable interfacial adhesion was formed between the $\mathrm{BI} p$ PBI layer and the Nafion layer. In conclusion, the Nafion protective layer improved chemical stability of the membrane from highly oxidizing $\mathrm{VO}_{2}{ }^{+}$ions even in an accelerated condition, and the hybrid interface formed from the acidbase complex did not increase the AR that much and decreased the vanadium permeability.

\section{Conflicts of interest}

There are no conflicts to declare.

\section{Acknowledgements}

This work was supported by the Program through the National Research Foundation of Korea (NRF) Grant funded by the Korean government (MSIT: Ministry of Science and ICT) (NRF2015M1A2A2056722) and the New\& Renewable Energy Core Technology Program (no. 20153030031670) and the Energy Efficiency \& Resources Core Technology Program (no. 20152010103210) of the Korea Institute of Energy Technology Evaluation and Planning (KETEP), granted financial resources from the Ministry of Trade, Industry and Energy, Republic of Korea.

\section{Notes and references}

1 C. Choi, S. Kim, R. Kim, Y. Choi, S. Kim, H.-y. Jung, J. H. Yang and H.-T. Kim, Renewable Sustainable Energy Rev., 2017, 69, 263-274.

2 M. Ulaganathan, V. Aravindan, Q. Yan, S. Madhavi, M. Skyllas-Kazacos and T. M. Lim, Adv. Mater. Interfaces, 2016, 3, 1500309.

3 M. L. Perry and A. Z. Weber, J. Electrochem. Soc., 2016, 163, A5064-A5067.

4 P. Alotto, M. Guarnieri and F. Moro, Renewable Sustainable Energy Rev., 2014, 29, 325-335.

5 A. Parasuraman, T. M. Lim, C. Menictas and M. SkyllasKazacos, Electrochim. Acta, 2013, 101, 27-40.

6 Z. Yang, J. Zhang, M. C. W. Kintner-Meyer, X. Lu, D. Choi, J. P. Lemmon and J. Liu, Chem. Rev., 2011, 111, 3577-3613.

7 M. Rychcik and M. Skyllas-Kazacos, J. Power Sources, 1988, 22, 59-67.

8 M. Skyllas-Kazacos and L. Goh, J. Membr. Sci., 2012, 399-400, 43-48.

9 B. Jiang, L. Wu, L. Yu, X. Qiu and J. Xi, J. Membr. Sci., 2016, 510, 18-26.

10 B. Jiang, L. Yu, L. Wu, D. Mu, L. Liu, J. Xi and X. Qiu, ACS Appl. Mater. Interfaces, 2016, 8, 12228-12238.

11 H. Y. Shin, M. S. Cha, S. H. Hong, T.-H. Kim, D.-S. Yang, S.-G. Oh, J. Y. Lee and Y. T. Hong, J. Mater. Chem. A, 2017, 5, 12285-12296.

12 S. Winardi, R. Sangeetha, M. Ohnmar Oo, Q. Yan, N. Wai, T. Lim and M. Skyllas-Kazacos, J. Membr. Sci., 2014, 450, 313-322.

13 S.-W. Choi, T.-H. Kim, S.-W. Jo, J. Y. Lee, S.-H. Cha and Y. T. Hong, Electrochim. Acta, 2018, 259, 427-439.

14 M. S. Cha, H. Y. Jeong, H. Y. Shin, S. H. Hong, T.-H. Kim, S.-G. Oh, J. Y. Lee and Y. T. Hong, J. Power Sources, 2017, 363, 78-86.

15 D. Zhang, X. Yan, G. He, L. Zhang, X. Liu, F. Zhang, M. Hu, Y. Dai and S. Peng, J. Mater. Chem. A, 2015, 3, 16948-16952. 16 M. S. Cha, J. Y. Lee, T.-H. Kim, H. Y. Jeong, H. Y. Shin, S.-G. Oh and Y. T. Hong, J. Membr. Sci., 2017, 530, 73-83. 
17 T. Luo, O. David, Y. Gendel and M. Wessling, J. Power Sources, 2016, 312, 45-54.

18 V. E. Sizov, M. S. Kondratenko and M. O. Gallyamov, J. Appl. Polym. Sci., 2018, 135, 46262.

19 S. Maurya, S.-H. Shin, J.-Y. Lee, Y. Kim and S.-H. Moon, RSC Adv., 2016, 6, 5198-5204.

20 Z. Yuan, Y. Duan, H. Zhang, X. Li, H. Zhang and I. Vankelecom, Energy Environ. Sci., 2016, 9, 441-447.

21 S. Peng, X. Wu, X. Yan, L. Gao, Y. Zhu, D. Zhang, J. Li, Q. Wang and G. He, J. Mater. Chem. A, 2018, 6, 3895-3905.

22 Z. Xia, L. Ying, J. Fang, Y.-Y. Du, W.-M. Zhang, X. Guo and J. Yin, J. Membr. Sci., 2017, 525, 229-239.

23 C. Noh, M. Jung, D. Henkensmeier, S. W. Nam and Y. Kwon, ACS Appl. Mater. Interfaces, 2017, 9, 36799-36809.

24 H. A. Pohl and R. P. Chartoff, J. Polym. Sci., Part A: Gen. Pap., 1964, 2, 2787-2806.

25 S.-K. Kim, T.-H. Kim, J.-W. Jung and J.-C. Lee, Polymer, 2009, 50, 3495-3502.

26 R. E. Rosli, A. B. Sulong, W. R. W. Daud, M. A. Zulkifley, T. Husaini, M. I. Rosli, E. H. Majlan and M. A. Haque, Int. J. Hydrogen Energy, 2017, 42, 9293-9314.

27 M. A. Haque, A. Bakar, K. S. Loh, E. H. Majlan, T. Husaini and R. Rosli, Int. J. Hydrogen Energy, 2017, 42, 9156-9179.

28 R. Ye, D. Henkensmeier, S. J. Yoon, Z. Huang, D. K. Kim, Z. Chang, S. Kim and R. Chen, J. Electrochem. Energy Convers. Storage, 2017, 15, 010801-010821.

29 D. Li, D. Shi, Y. Xia, L. Qiao, X. Li and H. Zhang, ACS Appl. Mater. Interfaces, 2017, 9, 8742-8750.
30 T. Luo, B. Dreusicke and M. Wessling, J. Membr. Sci., 2018, 556, 164-177.

31 J.-K. Jang, T.-H. Kim, S. J. Yoon, J. Y. Lee, J.-C. Lee and Y. T. Hong, J. Mater. Chem. A, 2016, 4, 14342-14355.

32 J. H. Kim, J. Choi, J. Seo, J. Kwon and U. Paik, J. Mater. Chem. A, 2016, 4, 11203-11206.

33 N. White, M. Misovich, A. Yaroshchuk and M. L. Bruening, ACS Appl. Mater. Interfaces, 2015, 7, 6620-6628.

34 X. Teng, J. Dai, J. Su, Y. Zhu, H. Liu and Z. Song, J. Power Sources, 2013, 240, 131-139.

35 M. Jung, W. Lee, N. Nambi Krishnan, S. Kim, G. Gupta, L. Komsiyska, C. Harms, Y. Kwon and D. Henkensmeier, Appl. Surf. Sci., 2018, 450, 301-311.

36 Y. Li, X. Li, J. Cao, W. Xu and H. Zhang, Chem. Commun., 2014, 50, 4596-4599.

37 Z. Mai, H. Zhang, X. Li, S. Xiao and H. Zhang, J. Power Sources, 2011, 196, 5737-5741.

38 J. grosse Austing, C. Nunes Kirchner, L. Komsiyska and G. Wittstock, J. Membr. Sci., 2016, 510, 259-269.

39 K. Oh, S. Won and H. Ju, Electrochim. Acta, 2015, 181, 238247.

40 Z. Yuan, X. Li, J. Hu, W. Xu, J. Cao and H. Zhang, Phys. Chem. Chem. Phys., 2014, 16, 19841-19847.

41 D.-S. Yang, J. Y. Lee, S.-W. Jo, S. J. Yoon, T.-H. Kim and Y. T. Hong, Int. J. Hydrogen Energy, 2018, 43, 1516-1522.

42 X. L. Zhou, T. S. Zhao, L. An, L. Wei and C. Zhang, Electrochim. Acta, 2015, 153, 492-498. 